\title{
A comparison of mutagenic potential of Aji-no-Moto with a traditional chemical mutagen on microsporogenesis in barley (Hordeum vulagre L.)
}

\author{
Vivek Singh \\ Department of Botany, Shri Jai Narain PG College, Lucknow - 226001 (Uttar Pradesh), \\ India \\ E. mail: viveksingh_2@yahoo.com
}

\section{Article Info}

https://doi.org/10.31018/

jans.v13i4.3042

Received: September 18, 2021

Revised: November 10, 2021

Accepted: November 15, 2021

\section{How to Cite}

Singh, V. (2021). A comparison of mutagenic potential of Aji-no-Moto with a traditional chemical mutagen on microsporogenesis in barley (Hordeum vulagre L.). Journal of Applied and Natural Science, 13(4), 1378 - 1382. https://doi.org/10.31018/jans.v13i4.3042

\begin{abstract}
Aji-no-Moto or Mono Sodium Glutamate (MSG) is a flavour enhancer being used extensively in South East Asian cuisine. The Federation of American Societies for Experimental Biology for the United States Food and Drug Administration (FDA) has concluded that MSG is safe when "eaten at customary levels" but there is still great confusion regarding its toxicity at higher concentrations. Therefore, it was decided to assess the mutagenic efficacy of MSG on a plant system and present the findings as a model for probably similar effects in the animal model. For this, a traditionally popular genus for genetic studies, Hordeum vulgare L. or winter barley, was used as the model system. The studies of microsporogenesis were done in order to see the long term effect. The sets were compared with experimental sets of plants grown from seeds treated with a traditional chemical mutagen Ethyl Methane Sulphonate (EMS). The study revealed that MSG does not induce much genotoxic effects at lower doses and the chromosomal damages induced were very few. However, at higher doses, it almost equals the effects of EMS in terms of heritable genetic damage. The work is significant as MSG continues to be one of the most popular flavouring agents and does not face any challenge to its biosafe status. However, the clastogenic and chromotoxic effects of higher doses of MSG as observed in the study are in total contradiction to the popular belief.
\end{abstract}

Keywords: Aji-no-moto, Barley, Chromosomal aberrations, EMS, Genotoxic, Monosodium glutamate

\section{INTRODUCTION}

"Aji-no-Moto, also known as Monosodium Glutamate or Sodium 2 - amino pentanedioate, is the sodium salt of glutamic acid $\left(\mathrm{C}_{5} \mathrm{H}_{8} \mathrm{NO}_{4} \mathrm{Na}\right)$. MSG is found naturally in some food including tomatoes and cheese" (Gov. of Canada, 2008; US FDA, 2012). MSG finds extensive use in South East Asian cuisine on account of its ability to enhance the spicy, salty flavour of natural foods like non-veg soups and stews (Ikeda 2002, Hayward 2016). It is said that "MSG balances, blends, and rounds the perception of other tastes" (Yamaguchi, 1991, Loliger, 2000). It was synthesized by Japanese biochemist Kikunae Ikeda in 1908 in an attempt to extract the taste of edible kelp called Konbu which is used as a base for various soups in Japan (Ikeda 2002).

Although, since its synthesis, MSG is being used continuously in various foods, still its biosafety has also been a matter of debate. Researches by different workers brought out two contrasting views about its effect on human health. For one group of researchers, it has long been accompanied with toxicity including its experimental genotoxic effects on plants and several metabolic disorders in human body ranging from headache, 'Chinese Restaurant Syndrome', to obesity, to even neurotoxic effects (Kamal et al., 2018). Its genotoxic effects had already been shown by many workers (Kumar and Paneerselvam, 2007; Turkoglu 2007; Nagwa et al., 2011; Renjana et.al. 2013; Hoda et al., 2015 etc).

However, another group of researchers finds it to be entirely safe for human consumption. Moreover, "it is metabolized by the human body exactly in a similar manner as the Glutamate because of the resemblance of the two" (Battaglia, 2000). Furthermore, FDA (Food and Drug Administration) had interpreted its safety based on the FASEB report (Walker and Lupien, 2000). It is well known that these agencies conduct a massive amount of tests and researches before issuing a safety certificate, still, long term, controlled and gene level investigations are needed for this compound. In the 
European Union, monosodium glutamate is classified as a food additive (E621) and regulations are in place to determine how and when it can be added to foods (EUFIC, 2002).

Considering the above-mentioned facts and also that Ethyl Methane Sulphonate (EMS, $\mathrm{C}_{3} \mathrm{H}_{8} \mathrm{SO}_{3}$ ) is a widely used monofunctional alkylating agent having one reactive group that reacts with DNA, the present research work was carried out to assess the mutagenic potentials of monosodium glutamate (MSG) by studying its mutagenic efficacy on Winter Barley Hordeum vulgare L. and comparing its effects of treatment with a wellknown chemical mutagen.

\section{MATERIALS AND METHODS}

The pure line seeds of Winter Barley $H$. vulgare $\mathrm{L}$. var K10 were obtained from the National Bureau of Plant Genetic Resources, New Delhi. The seeds were washed and soaked in tap water for $2 \mathrm{~h}$. Then they were transferred to different strengths of MSG and EMS. Suitable controls sets were soaked in tap water, which were left as such in darks chambers for 10 hours. The seeds were then washed again and planted in experimental pots with a 1:1 mixture of garden soil and leaf compost.

The strengths of chemicals used were $0.25 \%, 0.50 \%$, $0.75 \%$ and $1.0 \%$ MSG prepared by dissolving $2.5 \mathrm{~g} / \mathrm{l}$, $5.0 \mathrm{~g} / \mathrm{l}, 7.5 \mathrm{~g} / \mathrm{l}$ and $10.0 \mathrm{~g} / \mathrm{l}$ respectively in distilled water. Similar sets with $0.25 \%, 0.50 \%, 0.75 \%$ and $1.0 \%$ EMS were also prepared $(\mathrm{v} / \mathrm{v})$ for comparison. A suitable control set was also maintained where seeds were soaked in normal tap water.

The plants were raised normally and during the flowering season, their young buds were fixed in Carnoy's fluid (3:1 Absolute Alcohol: Glacial Acetic Acid). The fixed buds were later transferred to $70 \%$ ethanol and stored at $4^{\circ} \mathrm{C}$ for cytological studies.

The slides were prepared using Standard Acetocarmine Squash Technique and at least 1000 Pollen mother cells (PMCs) cells were studied in different fields to get average data for each set (according to Baker, 1958). Photomicrographs of the prominent chromosomal aberrations were taken from Nikon Optiphot 88 IC microscope with a fitted digital camera (40X magnification).

\section{RESULTS AND DISCUSSION}

The chromosomal abnormalities encountered, on the basis of 1000 PMCs studied per treatment set, were grouped in 5 categories depending upon the meiotic phases at which they occurred. Table 1 presents a comparative account of cytological behaviour in control; MSG and EMS treated barley plants ( $H$. vulgare). Meiosis was almost perfectly normal in control sets with the regular formation of the 7 bivalents at Metaphase I and

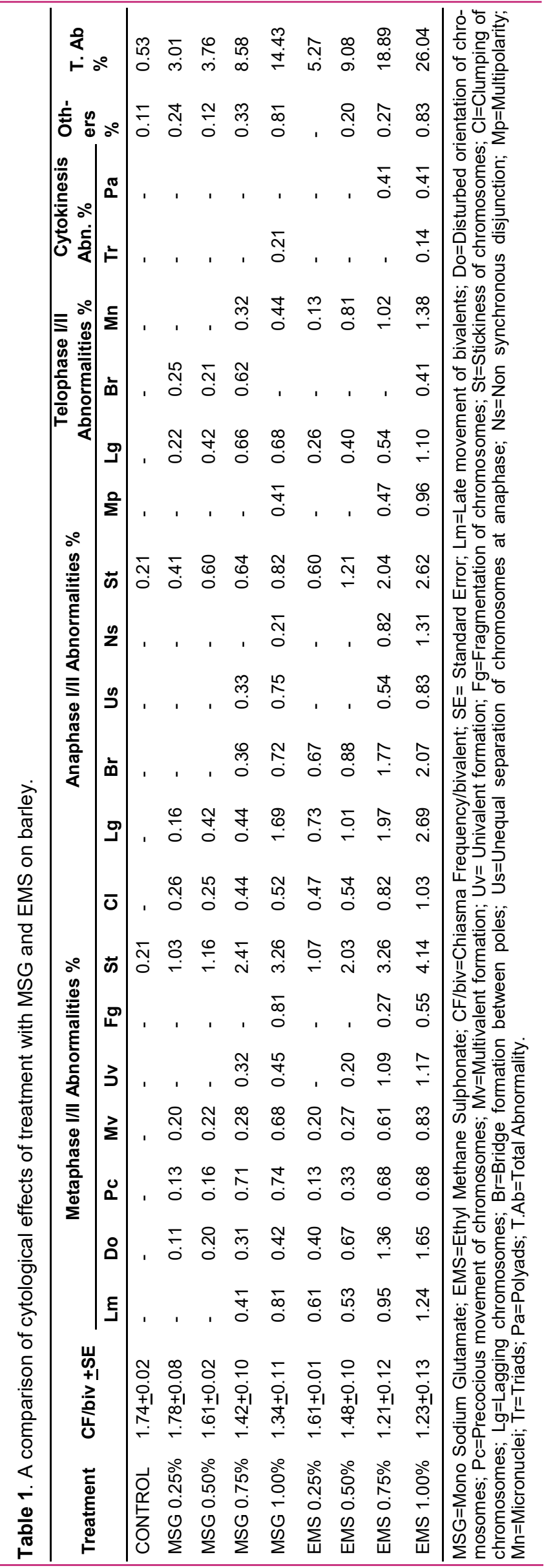


7:7 separations at Anaphase I.

All the treated plants showed varying degrees of abnormalities (Table 1). It was interesting to observe that the abnormalities like fragmentation, bridges, laggards, micronuclei etc., induced by MSG were very similar to those induced by EMS. However, the total percentage of each abnormality and total abnormality was lesser in MSG sets than in equivalent doses EMS. The chiasma frequency/biv was close to 2 in control which showed a downward trend in all treated sets except $0.25 \%$ MSG. The stickiness of chromosomes formed the most dominant of all anomalies both at Anaphase as well as Metaphase (Figs. 3,4,11). Its percentage was high even at the lowest dose set, being $1.03 \%$ in MSG $(0.25 \%)$ and a maximum value of $4.14 \%$ in the highest dose of the EMS (1.0\%). The values, although lower in MSG sets, were in a similar trend as in EMS sets. The case was almost similar at Anaphase I and II. Clumping of chromosomes was also frequent but not to the extent of stickiness.

Abnormalities related to spindle dysfunction (Figs. 1, 2, 9) were also common, with the highest frequency of late movement of bivalents to the Metaphase plate $(1.24 \%$ at $1.0 \%$ EMS). Disturbed orientation of bivalents was high at higher doses of EMS. It, however, was low in all sets of MSG. The overall frequency of abnormalities related to spindle dysfunction was lower. Multivalents and univalents (Figs. 1,2) were evident right from the lowest dose but in much smaller numbers. The percentage of multivalents in MSG sets was highest $(0.68 \%) 1.0 \%$ set. Few to many univalents could be seen in PMCs and their percentage increased with dose in EMS. Univalents showed consistency in both treatments. Fragmentation of chromosomes by heavy or moderate shredding was less frequent in MSG, but observed only at the highest dose of EMS to be $1.17 \%$.

Among Anaphasic anomalies, laggards, stickiness and bridges (Figs. 6, 7, 11) occupied the foremost position in both treatments. Laggards reached the highest value of $1.69 \%$ at MSG and $2.69 \%$ at EMS $1.0 \%$ set. Bridges also recorded a similar trend. Anaphase PMCs also exhibited high stickiness at Anaphase I and II. Nonsynchronous disjunction of chromosomes at Anaphase II could be observed in both treatments. Both unequal separation of chromosomes and multipolarity at Anaphase I, were of low occurrence.

The laggards and bridges observed at Telophase I and II might have persisted from Anaphase. Laggards were common, but bridges were seen only at the highest dose of EMS. Another common Telophase anomaly was the presence of micronuclei at the doses. Their percentage was high at $1.0 \%$ EMS set.

Cytokinesis revealed the limited presence of polyads and rare presence of triads along with normal tetrads at higher doses only. Other anomalies included cytomixis and transmigration of chromatin as well as shrinking of PMCs. Cytomixis was found in MSG in all doses, but the shrinking of PMCs was extremely rare. They were present only at the highest doses and their numbers were few.

Total abnormality percentage showed an exponential increase with dose in EMS and a gradual increase in MSG sets. In MSG lowest Total abnormality was 3.0\% in $0.25 \%$, which rose sharply to $14.43 \%$ at $1.0 \%$ set. This was, however much lower than EMS sets.

The mechanism that controls the mean number of chiasmata per bivalent and the distribution of chiasmata within bivalents can be influenced by the mutagens, and by the physiological changes in seed environment during germination (Bodmer and Parsons 1962; Jones 1987; Naseem and Kumar 2013). This could explain the differences in CF/biv observed in the study.

Stickiness was the most common of all chromosomal abnormalities. Mitra and Bhowmik (1996) also obtained high stickiness of chromosomes following chemical treatments. Sato and Gaul (1967) attributed clumping in EMS treated barley to a high level of stickiness where chromosomes lose identity and melt into each other, meaning that the chromosomes can no longer be identified separately. Gaul et al. (1966) and Tarar and Dhyansagar (1980) consider both stickiness and clumping as an effect of depolymerization of nucleic acids by mutagens. El Ghamery et al. (2003), while assessing the effect of Zinc on Nigella and Triticum, proposed that stickiness might also lead to incorrect folding of chromatin, leading to arrest of the cell cycle at Metaphase.

Fragmentation and breaks in chromosomes are important clastogenic effects of mutagens (Young and Young 1993). They can be interpreted as the result of chromosome stretching at points that are already fragile due to DNA damage. (Chauhan and Chauhan 1999).

Rao and Lakshmi (1980), while studying the effect of gamma rays on Capsicum, opined that "the presence of univalents in Metaphase I may be correlated to partial or complete lack of pairing between homologous chromosomes or due to early terminalization of chiasmata. In spite of the high degree of sterility, the visible chromosomal rearrangements like translocations and multivalents were rare. Precocious movement of univalents, lagging chromosomes and disturbed or unorientation of bivalents may be because of discrepancies of spindle formation (Patil and Bora 1961, Patil and Bhat 1992, Khan 1996) or failure of kinetochore to attach with spindle fibres (Amer and Ali, 1983).

Telophasic chromosomal aberrations included bi and multinucleate cells, micronuclei although not in a high frequency etc. Renjana et al. (2013) and Mitra and 


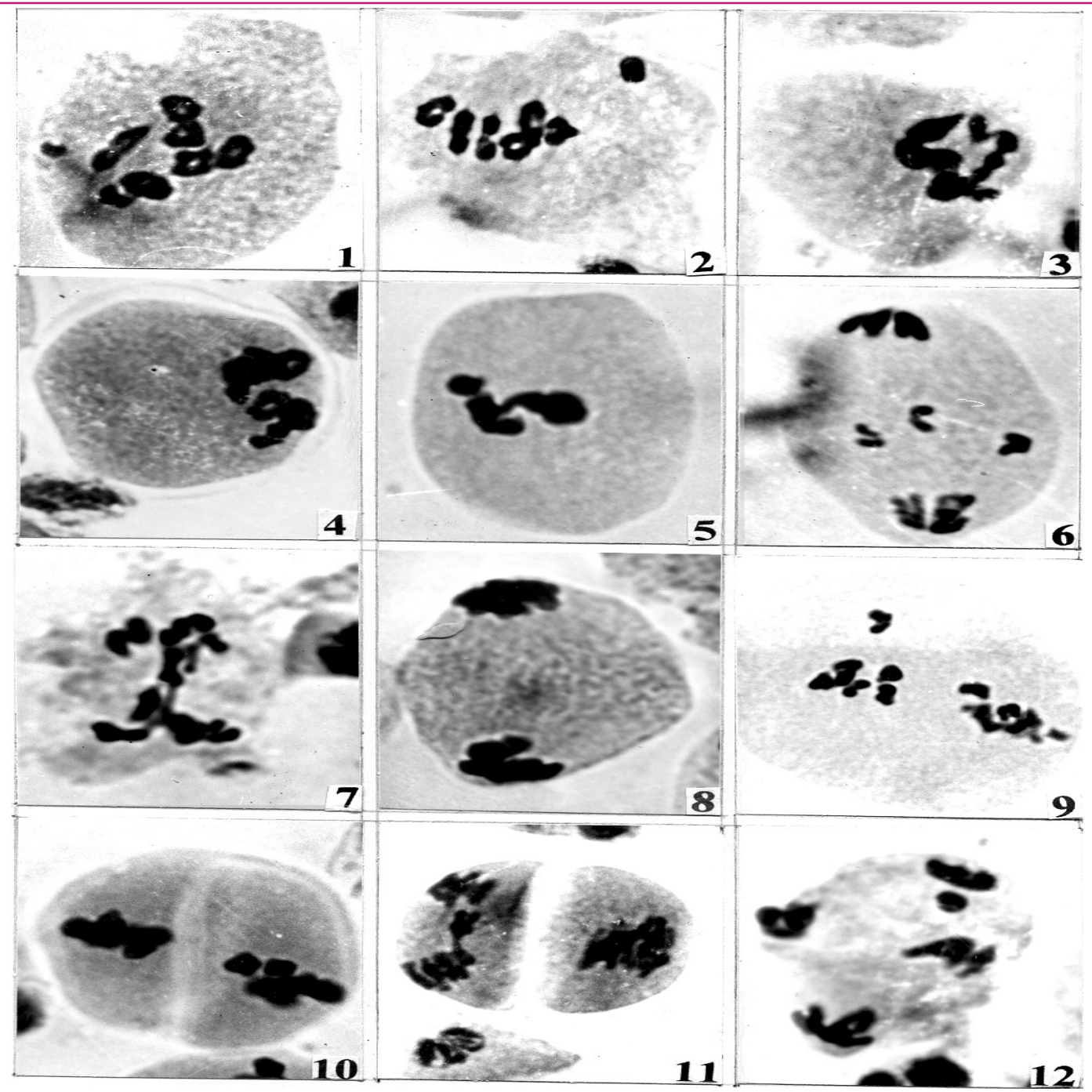

Figs.1-2. 1-2 Unorientation with univalent and multivalents at Metaphase I, 3-4 Stickiness of bivalents at Metaphase I, 5Clumping and Secondary Associations at Metaphase I, 6 -Laggards at Anaphase I, 7-Bridge at Anaphase I, 8 - Clumping at Anaphase I, 9- Unorientation at Metaphase II, 10-Clumping at Metaphase II, 11-Stickiness and bridge at Anaphase II, 12-Micronuclei at Telophase I/ of H. vulagre (Scale bar $1 \mathrm{~cm}=4 \mu$ )

Bhowmik (1996) have attributed micronuclei formation to acentric fragmented nuclear material clumping. Mutagenic inhibition of cell plate formation and cytokinesis appears to be the probable causes of the formation of binucleate and multinucleate cells (Borah and Talukdar, 2002). The reduction in chiasma frequency following chemical treatment, as observed in the present study, might result from mutagen induced structural changes. The reduction observed here is common to most mutagenic treatments (like EMS, MMS, $X$ rays, gamma rays, pesticides, heavy metals etc) and has been demonstrated by workers like Sinha and Mahapatra (1969) in Zea, Sree Ramulu (1971) in Sorghum, Sinha and Roy (1976) in Phaseolus and Lal and Srinivasachar (1979) in Pennisetum.

The present study showed a clear predominance of physiological abnormalities like stickiness and clumping over clastogenic ones like micronuclei (Fig. 12) in MSG sets. Such anomalies were common in EMS sets which led to the high degree of gamete sterility and brought the plant into a growth disadvantage. As a result, a high degree of lethality was induced even at low doses.

\section{Conclusion}

Assessment of the efficacy of any chemical as a mutagen is considered an important part of the safety protocol of chemicals. This becomes more important when the chemical in question is a drug, food additive, dye, flavouring agent, etc., it has to be directly consumed by the human population. In this context, based on a plant system, the present study concluded that MSG does not show many genotoxic properties at lower doses. This means that the damages induced were very few and mostly not clastogenic. However, at higher doses, it competes with the traditional mutagen for heritable genetic damage producing similar aberrations and in similar frequencies in some cases. But it must be taken into 
account that the plant systems can not be equivalent to animal systems, although they are quite similar.

\section{Conflict of interest}

The authors declare that he has no conflict of interest.

\section{REFERENCES}

1. Amer SM \& Ali EM. (1983). Cytological effects of pesticides XVII. Effects of insecticide dichlorv as on root mitosis of Vicia faba. Cytologia. 51, 21-25.

2. Baker, J. R. (1958). Principles of biological microtechnique. - London and New York.

3. Battaglia FC. (2000). Glutamine and glutamate exchange between the fetal liver and the placenta. J. Nutrition 130, 974-977.

4. Bodmer, W. F. \& Parsons, P. A. (1962). Linkage and recombination in evolution. - Adv. Genet. 11, 1-100.

5. Borah S.P. \& Talukdar J. (2002). Studies on the cytotoxic effects of extracts of castor seed (Ricinus communis L.). Cytologia. 67, 235-243.

6. Chauhan N. \& Chauhan A.K.S. (1999). Genotoxicity of fluoroquinolones in Allium cepa test system. J. Cytol Genet. 34, 153-160.

7. El-Ghamery A.A., El-Kholy M.A. \& Abou El-Yousser, M. A. (2003). Evaluation of Cytological effect of $\mathrm{Zn}^{2+}$ in relation to germination and root growth of Nigella sativa $\mathrm{L}$. and Triticum aestivum L. Mut. Res. Genet. Toxic.\& Environ. Mut. 537, 29-40.

8. EUFIC (2002). "The facts on Mono Sodium Glutamate". The European Union Food Information Council. 03 July 2002. (https,//www.eufic.org/en/whats-in-food/article/thefacts-on-monosodium-glutamate)

9. Gaul, K. Bender, K., Ulonaska, E. \& Sato, M. (1966). EMS induced genetic variability in barley, the problems of EMS induced sterility and method to increase the efficiency of EMS treatment in mutation breeding, IAEA, Vienna, 63-64.

10. Gov. of Canada (2008). "Monosodium glutamate (MSG) Questions and Answers". Government of Canada. 29 Jan 2008. (https,//www.canada.ca/en/health-canada/services/ food-nutrition/food-safety/food-additives/monosodiumglutamate-questions-answers.html)

11. Hayward, T. (2016). OMG I love MSG. Financial Times. Nikkei.

12. Hoda A. Khatab \& Nagat S. Elhaddad. (2015). Evaluation of Mutagenic Effects of Monosodium Glutamate using Allium cepa and antimutagenic action of Origanum majorana L. and Ruta chalepensis Medical Plants. British Biotechnology Journal. 8(1), 1-11.

13. Ikeda, K. (2002). New seasonings. Chem. Senses. 27 (9), 847-849.

14. Jones, G. H. (1987). Chiasmata. -In, Meiosis (ed P. B. MOENS), Academic Press, London, p. 213-244.

15. Khan, I. A. (1996). Meiotic irregularities induced by di ethyl sulphate (DES) in chilli pepper (Capsicum annum L.) var. NP 46 A. Prog. Hort. 28 (1-2), 36-40.

16. Kumar L.P. \& Panneerselvam N. (2007). Cytogenetic studies of food preservative in Allium cepa root meristem cells. Med. Biol. 14(2),60-63.
17. Lal J. \& Srinivasachar D. (1979). Induction of segmental interchanges in pearl millet (Pennisetum typhoides). Theoretical and Applied Genetics 54, 27-32.

18. Loliger J. 2000. Function and importance of Glutamate for Savory Foods. J. Nutrition 130 (4th Suppl), 915-920.

19. Mitra, P.K. \& Bhowmik, G. (1996). Cytological abnormalities in Nigella sativa induced by gamma rays and MS. J. Cytol. Gent. 31 , $205-215$.

20. Nagwa R.A., Magda A.M., Atef A.A., Elham A.A. (2011). Relative Mutagenecity of Some Food Preservatives on Plant Cells. Aust. J. Basic Appl. Sci. 5(12), 2817-2826.

21. Naseem S. \& Kumar G. (2012). Induced desynaptic variation in poppy (Papaver somniferum L.). Crop Breeding and Applied Biotechnology 13, 363-366.

22. Kamal N., Elizabeta Z. \& Jonathan, S. (2018). Extensive use of Monosodium Glutamate, A Threat to Public Health? EXCLI Journal. 17, 273-278.

23. Patil B.C. \& Bhat G.I. (1992). A comparative study of MH and EMS in the induction of chromosomal aberration on lateral root meristem in Clitoria tematea L. Cytologia. 57,295-264.

24. Patil, S.H. \& Bora, K.C. (1961). Meiotic abnormalities induced by $\mathrm{X}$-rays in Arachis hypogea. Ind. J. Genet. 21, $58-61$.

25. Rao, N. B. \& Laxmi, N. (1980). Gamma ray induced meiotic abnormalities in Capsicum annum L. Caryologia 33, 509 $-518$.

26. Renjana P.K., Anjana S. \& Thoppil E. John. (2013). Evaluation of genotoxic effects of baking powder and monosodium glutamate using Allium cepa assay. Int. J. Pharmacy \& Pharmaceutical Sci. 5 (2), 311-316.

27. Sato M. \& Gaul H. (1967). Effects of ethylmethane sulphonate on the fertility of barley. Rad. Bot. 7, 7-15.

28. Sinha S.K. \& Mohapatra B.K., (1969). Compensatory chiasma formation in maize. Cytologia 34,523-527

29. Sinha, S. S. N. \& Roy. H. (1976). Distribution of chiasmata between and within nuclei in irradiated and non- irradiated population in Phaseolus sp. J. Cytol. Genet. 11, 7-9.

30. Sree Ramulu, K. (1971). Effects of ionizing radiation and chemical mutagens on chiasma frequency in Sorghum. Cytologia 36, 543-541.

31. Tarar, J. L. \& Dnyansagar, V. R. (1980). Comparison of ethyl methane sulphonate and radiation induced meiotic abnormalities in Turnera ulmifolia Linn. var. angustifolia wild. Cytologia 45, 221-231.

32. Turkoglu S. (2007). Genotoxicity of five food preservatives tested on root tips of Allium cepa L. Mut. Res. 626, 4-14.

33. USFDA "Questions and Answers on Monosodium glutamate (MSG)". U.S. Food and Drug Administration. 19 Nov. 2012. (https,//www.fda.gov/food/food-additives-petitions/ questions-and-answers-monosodium-glutamate-msg)

34. Walker R. \& Lupien J.R. (2000). The Safety Evaluation of Monosodium Glutamate. The J. Nutrition. 130(4), 1049S$1052 S$.

35. Yamaguchi, S. (1991). Basic properties of umami and effects on humans. Physiology \& Behavior 49 (5), 83341.

36. Young S.W. \& Young P.W. (1993). Effect of plant growth regulators on mitotic chromosomes. The Nucleus. 36, 109 -113 . 